\title{
"ROMANOS PERO CRISTIANOS»: EL PROCESO DE "ROMANIZACIÓN" DEL CRISTIANISMO Y LAS SUPUESTAS PECULIARIDADES DE LA IGLESIA DE HISPANIA
}

\author{
POR \\ RAMÓN TEJA CASUSO ${ }^{1}$ \\ Universidad de Cantabria
}

\begin{abstract}
RESUMEN
Frente a la interpretación tradicional de que el cristianismo se impuso en el Imperio Romano porque logró aniquilar al paganismo, se defiende que más que aniquilación hubo un proceso de ósmosis y asimilación entre ambos "sistemas religiosos». En el marco de este proceso que el autor denomina «romanización» del cristianismo, se pretende refutar la tradicional interpretación, que se remonta a Adolf von Harnack, de una supuesta "mundanidad grosera y rigorismo fanático» que habría caracterizado la Iglesia española desde la Antigüedad.

PALABRAS CLAVE: cristianización; paganismo; romanización; asimilación; identidad.

\section{"ROMANS BUT CHRISTIANS": THE PROCESS OF "ROMANIZATION" OF CHRISTIANITY AND THE SUPPOSED PECULIARITIES OF THE CHURCH OF HISPANIA}

\begin{abstract}
Opposed to the traditional interpretation that Christianity prevailed in the Roman Empire because it managed to annihilate paganism, it is argued that more than annihilation there was a process of osmosis and assimilation between both "religious systems". Within the framework of this process that the author calls "Romanization" of Christianity, there is the intention to refute the traditional interpretation, which dates back to Adolf von Harnack, of a supposed "rude worldliness and fanatical rigorism" that would have characterized the Spanish Church since the Antiquity.
\end{abstract}

KEY WORDS: Christianization; paganism; Romanization; assimilation; identity.

Cómo CITAR ESTE ARTículo / CitATION: Teja Casuso, Ramón. 2021. "“Romanos pero cristianos": el proceso de "romanización" del cristianismo y las supuestas peculiaridades de la Iglesia de Hispania». Hispania Sacra LXXII, 147: 97-105. https://doi. org/10.3989/hs.2021.009

Recibido/Received 21-02-2019

Aceptado/Accepted 12-09-2019

Los Visigodos, decía Ortega y Gasset en su obra La España invertebrada, cuando llegaron a España estaban «alcoholizados de Romanismo». Su llegada se produjo al mismo tiempo que el hispano y cristiano Orosio escribía, en los años 416-417 por encargo de san Agustín, la primera historia de Roma desde una interpretatio cristiana. Pero ¿qué

\footnotetext{
1 ramon.teja@unican.es / https://orcid.org/0000-0002-6993-7091
}

significaba «cristiano» para Orosio? Suyas son estas afirmaciones transidas de juegos de palabras en que da a entender que las diferencias entre «cristiano» y «romano» eran algo que pertenecía al pasado pues había nacido ya una nueva respublica, fruto fecundo de la unión de pueblos que hablan la misma lengua y viven bajo las mismas leyes, una respublica que ya es cristiana pero a la que denomina Romania: ad Christianos et Romanos, Romanus et Christianus accedo... 
Inter Romanos Romanus, inter Christianos Christianus, inter homines homo, legibus imploro rempublicam, religione conscientiam, communione naturam. ${ }^{2}$

Para comprender la concepción historiográfica de Orosio se debe partir de la constatación de que en su obra alcanza su mejor expresión la idea de las múltiples ascendencias culturales de la denominada traslatio imperii: su objetivo es ensalzar los Tempora Christiana con una visión providencialista de la historia que hace coincidir la paz augustea con la llegada de Cristo. ${ }^{3}$ Si bien en algunos autores cristianos de los siglos II y III bajo el influjo de creencias milenaristas y apocalípticas de tinte antirromano, Roma era presentada como la última de las potencias hegemónicas cuyo puesto sería ocupado por un quinto imperio, mesiánico y eterno, en el siglo IV en autores como Eusebio de Cesarea, Jerónimo y especialmente Orosio desaparece el espíritu antirromano y se reafirma la aeternitas de Roma, señal de una profunda mutación cultural. ${ }^{4}$ Estamos muy lejos del siglo III cuando Orígenes consideraba que la posibilidad de que «convengan en un sentir único los griegos y bárbaros que habitan el Asia, la Europa o la Libia» solo se realizará cuando estén desprendidos de sus cuerpos. ${ }^{5}$ Desde su perspectiva, Orosio no solo devalúa el peligro de las empresas recientes de Alarico, sino que sueña con una confederación Romania - Ghotia en la que Roma, en cuanto depositaria de aquellos saberes jurídicos sine quibus respublica non est respublica, ejerciese una función claramente hegemónica. ${ }^{6}$

Me parece que es la misma idea que un joven historiador español ha expresado recientemente al tratar de describir la actitud cívica de paganos y cristianos al final del Imperio Romano: "Hoy en día resultaría absurdo proponer que un ciudadano cristiano del siglo IV considerara sus obligaciones políticas de una forma distinta a como lo haría un ciudadano pagano en el mismo contexto, al menos entre las élites aristocráticas de la ciudad, donde existía una cultura homogénea». ${ }^{7}$ Se trata de una interpretación muy alejada de la que con tanto éxito llevó a cabo Edward Gibbon cuando en su magna obra explicó la caída del Imperio por el hecho de que los cristianos, cuando pasaron a ser mayoría y dominantes, demostraron más fidelidad a su Dios que a Roma. Antes bien, como ha escrito Mar Marcos, «no podría acusarse a la jerarquía eclesiástica de "deslealtad al Imperio" y de ser la responsable final de su "caída" como hicieron ya los paganos que vivieron las invasiones y luego Gibbon convertiría en un tópico historiográfico de gran éxito». ${ }^{8}$

2 Orosio, Hist., V, 2, 3.

Por ello E. Peterson (1999) llegó a calificar el libro VI de sus Historiae como una "Teología de Augusto».

4 Vide Inglebert 1996, 299-300.

Orígenes, Contra Celso, XIII, 72.

Vide Zocca 2015, 231-232.

Andrés Pérez 2014, 338.

Marcos 2008, 633. Una prueba muy reveladora de la rápida identificación que se produjo entre Imperio Romano y cristianismo la tenemos en el juramento de los soldados a finales del siglo IV recogido por Vegecio: «Ellos juran por Dios, por Cristo, por el Santo Espíritu y por la majestad del emperador quien, el primero después de Dios, debe ser adorado y venerado por el género humano. En efecto, al emperador, desde que recibió el nombre de Augusto, le son debidas una fiel devoción y una sumisión incondicional como a un dios físicamente presente (praesenti et corporali deo)"; Vegecio, Institutiones rei militaris, II, 5.
Se podría objetar que, aunque histórica, la obra de Orosio es un texto apologético y con gran carga retórica, pero no es menos apologético y retórico que este otro de san Jerónimo cuando da entender que hacia el 400, al mismo tiempo que recordaba que la niña cristiana Paula era nieta del Pontifex Maximus Albinus, la Roma pagana había sido ya sustituida por la Roma cristiana. Este padre de la Iglesia latina se sirve de la imagen metafórica del Capitolio abandonado y suplantado por los sepulcros de los mártires como recurso poético de gran impacto simbólico para ilustrar la derrota de un sistema religioso por otro: «El dorado Capitolio está abandonado, todos los templos de Roma están cubiertos de hollín y telarañas. La ciudad tiembla en sus cimientos y el pueblo, que pasa en oleadas ante los santuarios semiderruidos, corre a los sepulcros de los mártires». ${ }^{9}$ Tan retórico como este texto de Jerónimo es este de Ambrosio de Milán cuando veinte años antes y en un contexto muy diferente declaraba que todos los viejos templos y santuarios de Roma seguían en pie. El texto forma parte de su polémica con el senador Quinto Aurelio Símaco y el obispo milanés pretendía hacer una defensa de la presunta tolerancia de los emperadores cristianos hacia los símbolos de la religión tradicional: Non illis satis sunt lavacra, non porticus, no plateae occupatae simulacris ?10 $^{10}$ En esta retórica que invade la apologética cristianismo-paganismo del final de la Antigüedad podemos incluir esta otra información salida de la pluma del rétor pagano, Libanio, cuando dice que Juliano, antes de acceder al trono en el 361, estaba muy triste «al ver los templos en ruina, los ritos desaparecidos, los altares destruidos, los sacrificios suprimidos y los bienes de los templos repartidos entre bribones». ${ }^{11}$ Podríamos recordar también estos versos de Paulino de Nola del año 405: «Los escuálidos simulacros tiemblan en los templos vacíos, sacudidos por las voces santas y golpeados por el nombre de Cristo. Temblorosos los demonios huyen de los templos abandonados...». ${ }^{12}$ Esta literatura que canta y ensalza el triunfo del cristianismo y la aniquilación del paganismo se explica quizá, como ha sugerido Rita Lizzi Testa, porque las iniciativas legislativas antipaganas de finales del S. IV favorecieron una ola de entusiasmo y euforia entre los cristianos dispuestos a interpretar el reinado de Teodosio como el cumplimiento providencial de todo lo que Constantino había iniciado con su conversión. ${ }^{13}$

El hispano e historiador Orosio no estaba solo, como hemos visto, al ofrecer la imagen triunfalista de un cristianismo romano. Pocos años antes, otro hispano, el aristócrata y poeta Prudencio, cantaba el dominio del mundo y la pax Romana porque el Dios cristiano así lo había decidido:

¡Oh, ven Omnipotente, desciende a la tierra en concordia! Ya te recibe, oh Cristo, el mundo, al que la paz

9 Jerónimo, Epist., 107, 1: Auratum squalet Capitolium, fuligine et aranearum telis omnia Romae templa coperta sunt. Movetur Urbs sedibus suis, et inundans populos ante delubra semiruta currit ad martyrum tumulos.

10 Ambrosio, Epist., 18, 31.

11 Libanio, Orat., 18, 23.

12 Paulino de Nola, Carmen, XIX, 69-72: In vacuis simulacra tremunt squalentia templis / vocibus iucta piis impulsaque nomine Christi. / Diffugiunt trepidi desertas daemones aedes...

13 Lizzi Testa 2009b, 127. Sobre el universalismo religioso y cultural que caracterizó el final de la Antigüedad, muy alejado de visiones apologéticas, vide Acerbi 2017. 
y Roma mantienen en apretado nudo (quem congrege nexu pax et Roma tenent). Estas dos cosas ordenas Tú que sean cabeza y cumbre (capita et culmina) del universo, pues ni Roma sin paz halla favor en ti (nec Roma tibi sine pace probatur), y la excelsa autoridad de Roma (excellentia Romae) hace que la paz te complazca. ${ }^{14}$

Y parece que fue también Prudencio el primero que llevó a cabo la asimilación de la pareja Pedro y Pablo con la romana de Rómulo y Remo al que siguió Paulino de Nola y sobre todo León Magno, el autor de un famoso Sermo 82 con motivo de la fiesta de los Apóstoles el 29 de junio del 441 , la misma fecha en que eran conmemorados los gemelos fundadores de Roma. Fue también Prudencio el primero que cantó no solo las excelencias de un cristianismo romano sino también las de un cristianismo hispano cuando en el himno en honor de san Fructuoso hace esta proclama que tanto eco tendrá en época moderna: Hispanos Deus aspicit benignus. ${ }^{15}$

Con estas consideraciones previas pretendo dar respuesta a una de las demandas históricas que durante siglos han atraído e incluso torturado la mente de todo tipo de historiadores: ¿por qué triunfó el cristianismo? Como una simple muestra de la variedad de respuestas, me limitaré a recoger dos cuyos autores que están separados por más de un siglo, un teólogo alemán y un sociólogo norteamericano. El primero no es otro que el famoso Adolf von Harnack, el más importante representante de la teología liberal protestante y del modernismo de comienzos del siglo XX. Su conocida obra Die Mission und Ausbreitung des Christentums in den ersten drei Jarhundarten (1902) concluye con este largo manifiesto en el que, al igual que en los apologetas primeros del cristianismo, se dan la mano la retórica y la apología:

Hemos intentado descifrar los motivos de esta sorprendente propagación; estos deben buscarse, a mi parecer, por un lado, en lo que constituye el alma y la esencia de la nueva religión - el monoteísmo y el Evangelio - y, por otro, en la gran variedad y riqueza de sus elementos y en su maravilloso poder de adaptación. Pero en qué medida influyeron cada uno de los aspectos, cuánto fue debido al monoteísmo espiritualista, al anuncio de Jesucristo, a la esperanza de la Resurrección, a la caridad activa y a la beneficencia, a la disciplina y a la organización, a la tendencia y carácter sincrético, a la capacidad, alcanzada en el s. III, de superar en atractivo cualquier otro culto o superstición, todo esto escapa a nuestra capacidad de análisis [...] Era religión universal en el doble sentido de que respondía a las necesidades comunes de todos y a las de cada uno en particular. Se convirtió en Iglesia, Iglesia universal, y se sirvió de todas las fuerzas que hay en el mundo, salvo de la espada. Permaneció exclusivista y, sin embargo, atrajo todos los elementos extraños que tenían algún valor. In hoc signo venció, pero, por encima de todas las cosas humanas, eternas y perecederas, puso el sello de la Cruz $(1986,554)$.

\section{Prudencio, Contra Símaco, II, 643-638.}

15 Prudencio, Peristephanon, VI, 4. Parece haberse inspirado en esta frase de Prudencio el jesuita P. Hoyos cuando recibió la revelación del Sagrado Corazón de Jesús: «Reinaré en España con especial predilección sobre otras naciones» o también esta declaración de Pio XII en 1939: «España es la nación elegida por Dios como baluarte inexpugnable de la fe».
Muy recientemente el sociólogo americano Rodney Stark ha publicado un libro titulado The Raise of Christianity. A Sociologist Reconsiders History que concluye el tema de la expansión del cristianismo con estas palabras:

El cristianismo no creció porque los milagros influyesen en las plazas de los mercados (aunque sí pudo haber algo de eso), o debido a que Constantino dijo que sí, o incluso a causa de que los mártires le otorgaron tanta credibilidad. Se expandió porque los cristianos constituyeron una comunidad intensa, capaz de generar esa «invencible obstinación» que tanto ofendía a Plinio el Joven, pero que proporcionaba inmensas recompensas religiosas. $Y$ los medios esenciales de su crecimiento fueron los esfuerzos mancomunados $y$ motivados del creciente número de creyentes cristianos, que invitaban a sus amigos, parientes y vecinos a compartir la «buena nueva» (Stark 2009, 190).

Tanto el texto de von Harnack como el juicio del sociólogo americano se parecen más a las interpretaciones apologéticas de un Jerónimo de finales del siglo IV que he citado al comienzo que a un análisis histórico riguroso. Con toda su carga retórica, el juicio de von Harnack constituye más una alabanza confesional de la nueva religión que un análisis de las causas de su expansión. Al final termina por imponerse en su pensamiento el elemento sobrenatural o providencial frente al puramente histórico. Pero lo que más sorprende es que mientras que von Harnack era un teólogo, Stark es un sociólogo que se confiesa "aficionado a la historia» y que manifiesta que se sintió interesado por el tema del cristianismo a raíz de la lectura del libro de Wayne Meeks, The First Urban Christians. Pienso por ello que en la conclusión que he citado demuestra no haber comprendido casi nada de lo que fue el cristianismo en los primeros siglos. Para él se trató una especie de religión de amigos, clientes y tertulianos y fruto de lo que denomina, con una mentalidad muy americana, las "oportunidades del mercado religioso». Uno y otro desconocen, por ejemplo, que, cuando Peter Brown publicó la reseña del volumen «El conflicto entre paganismo y cristianismo en el siglo IV» de Arnaldo Momigliano eliminó toda idea de conflicto y enfrentamiento y privilegió términos como ósmosis, intercambio, transformación y transición religiosa.

Me propongo no una solución sino una reflexión en voz alta sobre un tema tan complejo y debatido: me planteo no tanto por qué se impuso el cristianismo como religión en el Imperio Romano y en Hispania en cuanto parte del Imperio, sino explicar, o mejor constatar, el proceso que condujo a que ese "sistema religioso" iniciado en Judea, centrado en la figura de un hombre condenado a muerte por el poder legítimo romano, terminase por considerarse tan romano como el propio Augusto durante cuyo reinado nació. Prefiero servirme del término "sistema religioso» en vez del tan abusado e impreciso como «religión» o religio, pues, cuando lo utilizamos los historiadores, deberíamos preguntarnos con qué significado nos servimos de él, a saber, si "étnico», "religioso» o "cultural» y lo mismo podría decirse del término «paganismo» (Teja 2015, 112). ${ }^{16}$

16 Me remito aquí a Sachot 1998, cuando dice que el concepto religio es solo uno de los sistemas conceptuales posibles con que una determinada cultura y, a partir de Tertuliano, la latina, interpretó el cristianismo. Creo que los grandes avances que se han hecho en los 
Rodney Stark parte en la citada obra del mismo error del que han partido la mayor parte de los estudiosos modernos, la idea de que el cristianismo triunfó porque aniquiló al paganismo y recurre a la autoridad de dos ilustres colegas norteamericanos para afianzarla. Así en las páginas 179-180, después de citar a E. Dodds y R. MacMullen afirma tajantemente: "Cito a estos dos distinguidos estudiosos para ilustrar el consenso generalizado entre los historiadores de que el paganismo fue aniquilado por el cristianismo y que la conversión del cristianismo fue la estocada mortal». Repito que afirmaciones como estas no hacen sino reiterar argumentos apologéticos como los que he recordado de los autores cristianos de finales del siglo IV, pero contradicen totalmente el pensamiento de un historiador, aunque apologeta también y cristiano, como Orosio, pues se trata de una pregunta que ni se planteó ni inquietó la mente del historiador hispano. Para Orosio lo que había sucedido es que se había culminado el proceso de la identificación entre el derecho, la mentalidad y la cultura romana con el nuevo nomen cristiano: «El ancho Oriente, el abundante Septentrión, el vasto Sur y los muy fértiles y seguros lugares de las grandes islas me pertenecen en virtud del derecho (romano) y del nombre (cristiano) porque me acerco a los romanos y a los cristianos como romano y cristiano (ad Christianos et Romanos ut Christianus et Romanus accedo) $).{ }^{17}$ En apoyo de la interpretación de Orosio me atrevo a evocar lo que Robin Lane Fox ha denominado "segundo paganismo» o «nueva religiosidad» de los siglos III-IV y que Aline Rouselle (1997, 17-18) ha desarrollado en estos términos. "Le paganisme s'est mantenue partout, tant le dieux locaux, ancestraux, civiques et non civiques que les dieux importés dans les diverse régions del'empire. Les santuaires ruraux, les lieux sacrés de prières, de guerison, à l'écart des villes, en Orient comme en Occident, ont conservé leur fonction».

El «sistema religioso» que denominamos paganismo no fue aniquilado por el cristianismo, sino que fue asimilado e integrado por este hasta constituir un sistema nuevo con un nombre nuevo. Es la idea expresada por Peter Brown cuando desarrolló la teoría de que el cristianismo había sido conquistado por el mundo, y no viceversa (Brown 1974). De algún modo lo había reconocido el mismo von Harnack cuando afirmó, aunque no hay constancia de ello en ninguno de sus escritos, que «paganos y cristianos compartían una misma teología aunque diferían en las mitologías», si bien habría que matizar también esto último. Si aceptamos esta interpretación, habría que dar la razón a un español, cristiano pero antitrinitario como Miguel Servet, cuando afirmó que la cultura y pensamientos grecorromanos anularon el mensaje de Cristo y los cristianos pasaron a compartir la misma teología que los paganos de la Antigüedad Tardía. ${ }^{18}$

Se explica así también otra de las preguntas que una y otra vez acostumbran a plantearse los historiadores: cómo y por qué un sistema religioso como el cristiano una vez que

últimos años en la investigación sobre los orígenes del cristianismo y sus relaciones con el judaísmo, podrían servir de modelo para analizar también las relaciones entre ambos sistemas religiosos, el "pagano» y el "cristiano» al final de la Antigüedad. En este sentido, hago mía la afirmación de Pesce 2011, 150, cuando afirma que «il concetto di "sistema religioso" permette di affrontare in modo più concreto il problema della transizione da una religione all'altra».

17 Orosio, Hist., V, 2, 3.

18 Servet, De Trinitatis Errorribus, 111. se asentó en el poder, pasó de perseguido a perseguidor. ${ }^{19} \mathrm{~A}$ partir de Teodosio I se impuso de tal forma el dogma niceno que quienes lo negaran pasaron a ser enemigos no solo de la Iglesia sino también del Imperio y estos principios fueron después asumidos con enorme rapidez por los denominados pueblos bárbaros, como los visigodos de Hispania, a pesar de que no aceptaban el credo de Nicea. Las diferencias teológicas cedieron ante las exigencias del derecho y fueron los visigodos una vez asentados en Hispania los primeros en aplicar, incluso con más dureza (más «bárbaramente» se podría decir), las leyes romanas contra los judíos y los herejes: la herejía se constituyó al mismo tiempo en pecado, delito eclesiástico y crimen político y social. Partiendo de este precedente, una vez que la Universidad de Bolonia comenzó a recuperar, a partir del siglo $\mathrm{XI}$, los principios del viejo derecho romano, base del derecho eclesiástico medieval y del posterior derecho canónico, se justificará la persecución de la inquisición francesa contra cátaros y todo tipo de «herejes». Habría que darle una vez más la razón a Miguel Servet $-\mathrm{y}$ después de él a Bartolomé de las Casas- cuando afirmaba en contra de los protagonistas de la denominada «Reforma luterana radical», según la expresión acuñada por Georges Williams, como Calvino y el propio Lutero, que la intolerancia religiosa que caracterizó al cristianismo desde que este se hizo "romano» no tenía ninguna base Bíblica ni Evangélica. Como reconocerá Tomás de Aquino, fue san Agustín quien hacia el año 400, después de haber defendido con anterioridad que «nadie debe ser obligado a la unidad de Cristo, sino que hay que actuar con la palabra y luchar con el debate ${ }^{20}$ culminó su giro copernicano o caída del caballo justificando el gravísimo paso en falso del recurso a la violencia para reprimir a los herejes circunceliones: Agustín, al no encontrar argumentos escriturísticos, recurrió a la interpretación simbólica de la parábola de los invitados a la cena con el famoso "oblígalos a entrar» (compelle intrare) de Lc $14,23 .{ }^{21}$

Si me he referido a dos nombres españoles como Servet y De las Casas es porque con mucha frecuencia se ha aducido, sin fundamento, que el recurso a la represión violenta del disidente fue una de las características de cristianismo español de todos los tiempos. El recurso a la violencia en materia religiosa había penetrado de tal forma en las mentes de todos los cristianos a lo largo de la Edad Media que ni siquiera Lutero y Calvino se dieron cuenta de que se trataba de uno de los más antiguos y atávicos vicios "romanos» que ellos mismo hicieron suyo y cuya primera víctima fue $\mathrm{M}$. Servet y dio origen a esta frase, inmortal por su claridad, de Sebastian Castellio, contra Calvino: "Matar a un hombre no es defender una doctrina, es matar a un hombre».22

19 De entre la innumerable bibliografía sobre el tema, me remito a los diversos estudios recogidos en Fernández Ubiña y Marcos 2007; vide el volumen de Canella 2017, especialmente el capítulo «ll giro di vite»: $109-180$ y el capítulo "Intolérance religieuse et christianisme: remarques sur une paradoxe» en la edición francesa de Stroumsa 2017, 113-138.

20 Agustín, Epist., 93, 5 ad Vincentium: Neminem ad unitatem Christi esse cogendum, verbo esse agendum, disputatione pugnandum; citado en Tomás de Aquino, Summa Theologica, 2-2, q. 10, a.8. Ad primum.

21 Vide Marcos 2013; Stroumsa 1994.

22 Vide Zweig 2001, 196. 
Volviendo a la época romana me vuelvo a plantear qué sentido tiene decir que el cristianismo liquidó al paganismo y qué fundamentó los sorprendentes juicios que se han expresado sobre el cristianismo hispano. Fue Adolf von Harnack que, como dije anteriormente, confunde su condición de historiador con la de teólogo y apologeta, el que quizá más ha contribuido a formar una idea que arraigó mucho en la historiografía sobre el cristianismo hispano de la Antigüedad: la identificación del cristianismo de la Hispania romana con una mundanidad profana, es decir, con el paganismo, por un lado, y con un rigorismo e intolerancia fanática por otro. Este es su juicio expresado en la obra citada (1986, 540):

Hemos visto ya que el primer documento que poseemos sobre la Iglesia de España (la epístola de Cipriano a las comunidades de León y Mérida) la muestra contaminada con peligrosos elementos profanos; pues bien, esto recibe una confirmación en los 81 cánones de Elvira. Y también en estos se advierte el contraste, característico de la Iglesia española de todos los tiempos (sic), entre una mundanidad grosera y un rigorismo fanático....

Si examinamos los vicios que el sabio alemán achaca a la Iglesia española para justificar la supuesta «mundanidad grosera» vemos que se trata de una serie de prácticas que aparecen condenadas, no justificadas, en los cánones de Elvira, y que encontramos repetidas en los cánones de otros muchos concilios de los siglos IV y $\mathrm{V}$ a lo largo y ancho del Imperio y en autores como Cipriano de Cartago sobre el cristianismo africano. Me permito citar el largo pasaje del historiador alemán:

La mundanidad de la Iglesia española y el peligro de sacrílegas dedicaciones al culto pagano se manifiestan en el hecho notable de cristianos que no rechazaron el ejercicio del flaminado y otras altas dignidades sacerdotales paganas, así como el duunvirato; y se manifiestan también en los delitos que son cometidos por aquellos cristianos: patrones que atormentan hasta la muerte a sus esclavas, homicidios, qui maleficio interficiunt, culpas carnales de las más abyectas, adulterios y relajación del vínculo matrimonial, proxenetas, fornicación de vírgenes consagradas, padres que casan a sus hijas con sacerdotes paganos, obispos y clérigos fornicarios y adúlteros, esposas de clérigos adúlteras, clérigos que ejercen el comercio y frecuentan los mercados, clérigos usureros. Significativa es también la prohibición de encender cirios de día en los cementerios y la prohibición a las mujeres de pernoctar en los cementerios. La prohibición de pinturas en las iglesia hace pensar en suntuosas basílicas y en un culto paganizante a las imágenes; se fijan en la iglesia libelos irrisorios e infamantes; se presupone la existencia de cristianos que son grandes propietarios de tierras que toleran que sus arrendatarios deduzcan del alquiler el precio dedicado a los dioses protectores de la agricultura; hay otros que dejan a sus esclavos con sus ídolos o que hacen bendecir sus campos por judíos; hay cristianos que no se preocupan de frecuentar la iglesia, catecúmenos que durante mucho tiempo no vienen a la iglesia, cristianos que como los gentiles acceden al Capitolio para sacrificar o que son jugadores habituales. Estos ejemplos, termina diciendo, "son suficientes para darnos una idea de la mundanidad y, por lo tanto también de la difusión del cristianismo en España antes de Constantino». Sigue enumerando otras anomalías que paso por alto y concluye con este juicio: «La Iglesia española puede haberse constituido al mismo tiempo que la romana, pero durante mucho tiempo no hizo nada que fuese digno de ser recordado y, cuando entra en la luz de la historia, sabemos que las cosas que pasan no la honran [...] Sabemos que a finales del siglo IV la Iglesia de España se encontraba en condiciones muy tristes. En ningún país el ascetismo monástico - forma en aquella época del más sincero sentimiento cristiano- encontró tanta resistencia como en el clero español» (Harnack 1986, 541-542).

No tengo aquí espacio para refutar la interpretación de los cánones de Elvira en que se basa von Harnack, pero creo que la mejor interpretación de estos cánones es la que hizo Manuel Sotomayor (1982) cuando manifestó que quienes aquí son denunciados eran "romanos pero cristianos», es decir, ciudadanos romanos insertos en todos los aspectos sociales culturales y políticos en una época sustancialmente pagana, no un grupo aparte. ${ }^{23}$ Pero lo más sorprendente es que sus juicios hayan sido repetidos hasta nuestros días sin el menor espíritu crítico en la historiografía posterior, aunque no me consta que hayan citado nunca al teólogo alemán. Me limitaré a reproducir algunos juicios recogidos por mí hace tiempo en un estudio en que llevé a cabo una especie de sondeo entre estudiosos de diversa procedencia e ideología. El francés Jacques Fontaine $(1981,196)$ ha escrito: «La tragedia de Prisciliano se explica por los extremismos opuestos alcanzados en Hispania - a un nivel que quizá no se encuentra en otras provincias de Occidente-, por la mundanización de una parte del alto clero y por unas conversiones apasionadas a un evangelismo y ascetismo intransigente»; por las mismas fechas, el italiano Guido Clemente $(1994,63)$ escribía: «Già Cipriano lamentava in una lettera la mondanità del cristianesimo spagnolo e il concilio di lliberris, intorno al 300, ne é la prova più evidente»; con posterioridad, el español José María Blázquez (1996, 392) afirmaba: «La Iglesia hispana dio prueba en este concilio (EIvira) de una gran mundanidad y de un riguroso ascetismo». Por su parte, Victor C. de Clercq en su clásica monografía sobre Osio de Cordoba $(1954,58)$, añade a la «mundanidad» el «nepotismo» como una característica del cristianismo hispano, ignorando que era característico del cristianismo desde sus inicios: "The marked tendency in the early spanish Church to render episcopate hereditary in some local preminent familiy». Ya entonces emití el juicio de que estos análisis del cristianismo hispano constituían una forma de "colonialismo científico» pues los historiadores extranjeros habían intentado de alguna manera llenar el vacío existente en la historiografía española lanzando interpretaciones con escaso fundamento histórico que, en el caso del cristianismo, constituyen una simple proyección hacia el pasado de prejuicios muy arraigados sobre la Iglesia española de épocas posteriores (Teja 2000, 30).

Von Harnack parte de la creencia de que existían cristianos perfectos que identifica con los anteriores a Constanti-

23 Podría consultarse también el artículo de Fernández Ubiña 1993. Además habría que haber recomendado a von Harnack la lectura del artículo de L. Duchesne 1887 sobre el Concilio de Elvira y los flamines cristianos. También podría haber tenido en cuenta la denuncia por parte de Cipriano de Cartago (De lapsis, 5-6) sobre la baja moralidad del clero africano de su época al que atribuye muchos de los vicios denunciados por los cánones de Elvira. 
no, los de la llamada «era de los mártires» y después con los protestantes surgidos de la Reforma. Pero se trata de una falacia historiográfica y me limitaré a recoger este juicio de Robert Markus, uno de los mejores conocedores modernos del cristianismo de la Antigüedad. Afirma Markus que «la imagen de una sociedad claramente dividida en "cristiana" y "pagana" es una creación de los cristianos más tardíos de finales del siglo IV y ha sido asumida demasiado pronto por los historiadores modernos»; "en torno al 350», sigue diciendo, "era muy poco lo que separaba a un pagano de un cristiano en la sociedad romana», y añade la siguiente enumeración que podemos cotejar con la de von Harnack:

Los bailes, las celebraciones lúdicas, con manifestaciones, a veces en los cementerios, el teatro, los juegos, la presencia en los baños, una gran variedad de prácticas mágicas y cosas semejantes, que con frecuencia provocaban sospechas y denuncias por parte de los obispos (como los de Elvira se podría añadir). Pero todo esto formaba parte de aquel vasto «territorio común» que los cristianos heredaron del pasado pagano (Markus 1990, 27-28).

Sobre este «territorio común» me permito recordar algunos datos: salvo en Portugal, en todos los países «cristianizados», los días de la semana siguen llevando los nombres de las divinidades paganas; a pesar de las críticas de los predicadores cristianos como Martín de Braga, continuamos celebrando el inicio del año según costumbre muy arraigada desde la época de la República, en las Kalendas de enero y no en el equinoccio del 25 de marzo como propugnaba este obispo; en el IV concilio de Toledo del 633, can. 11, ante la imposibilidad de eliminar las Kalendas, se establece que ese día se dedique al ayuno y la abstinencia, pero, al parecer, con muy escaso éxito. Tenemos también constancia, como han demostrado Chastagnol y Duval (1972), de que en el África del siglo $\mathrm{V}$ muchos sacerdotes del culto imperial continuaban con el mismo nombre, ejerciendo las mismas funciones a pesar de ser ya cristianos y también que en el 400, el papa Inocencio I reconocía la existencia de sacerdotes del culto imperial cuando escribe a los obispos reunidos en el concilio de Toledo de ese año: «no se debe promover a los órdenes a los curiales que, después de su bautismo, han sido coronati, han ejercido el sacerdocio, como se dice, (vel coronati fuerint, vel sacerdotium quod dicitur sustinuerint) y celebrado juegos públicos» (Duchesne 1887, 172-173). Cabe preguntarse por ello, como ha hecho Rita Lizzi Testa, si pontífices y augures romanos de cuya actividad tenemos pruebas hasta finales del siglo IV no habrían podido compartir con obispos y presbíteros cristianos sus propias funciones, del mismo modo que también el emperador terminó por compartir con los obispos y el papa la gestión de lo sagrado en el Imperio. Además, señala la estudiosa italiana, «la asimilación progresiva de los sacerdotes cristianos a sus antiguos colegas en el lenguaje formular, en la vestimenta, en la forma de comportarse provocaron transformaciones y transiciones más bien que conflictos y rupturas» (Lizzi Testa 2009a, 190).

Me permito recordar, como indiqué anteriormente, que fue León Magno quien instituyó la fiesta de Pedro y Pablo para competir con la de Rómulo y Remo y quiero recordar también un famoso sermón del mismo León de mediados del siglo V (451) sobre la Navidad que ha sido citado y uti- lizado recientemente por Silvia Acerbi (2018). Advierte el papa a sus fieles romanos sobre la que considera costumbre pagana según la cual «el Sol que se eleva al despuntar la primera luz del día es venerado por ciertas personas insensatas desde lugares situados en lo alto». Pero la denuncia del papa romano no afecta solo a los paganos que sobrevivían en Roma, sino que el papa critica que la práctica de adorar al Sol naciente estaba muy arraigada también entre los cristianos que acudían a la basílica de San Pedro llevados de su religiosidad (religiose facere putant):

Antes de entrar a la basílica del Apóstol Pedro, que está consagrada al Dios único, vivo y verdadero, y tras haber superado los peldaños que dan acceso a la explanada de la parte superior, vuelto su rostro hacia el Sol naciente, hacen una reverencia e inclinan la cabeza en honor del esplendoroso disco (converso corpore ad nascentem solem se reflectant, et curvatis cervicibus in honorem se splendidi orbis inclinent). Esto sucede, en parte por ignorancia, en parte por espíritu de paganismo (partim ignorantiae vitio, partim paganitatis spiritu). Termina el papa afirmando que le induce a denunciar esta costumbre el peligro de que a los fieles convertidos se les induzca a creer que "se trata de algo compartido por cristianos y paganos (christianis et impiis viderit esse communem) $\gg .^{24}$

Medio siglo más tarde el papa Gelasio (492-496) se dirigía en una epístola a sus interlocutores reprochándoles el culto de los Dióscuros durante las fiestas de las Lupercalia del 15 febrero: «¿Por qué vuestros Cástores, a cuyo culto no habéis querido renunciar no os han hecho propicios los mares? ${ }^{25}$ El destinatario de la epístola es Andrómaco, uno de los promotores de las Lupercales que se declaraba cristiano y al cual el papa no excluyó de la comunidad. ${ }^{26}$ Resulta significativo que los interlocutores de Gelasio, responsables de la celebración de las fiestas son definidos por este como nec christiani nec pagani. ${ }^{27}$

Pienso que el spiritus paganitatis del que hablaba León o los nec pagani nec christiani de Gelasio o bien el «territorio común» entre paganos y cristianos de R. Markus expresan bien lo que me atrevo a denominar «paganización del cristianismo». No está de más recordar que, a pesar de los temores del pontífice León, el culto solar ha inspirado profundamente la liturgia cristiana, especialmente de la Pascua de Resurrección y de la Natividad, como puso ya de relieve Dölger en su famosa obra «Sol salutis» y posteriormente Rahner (1990). Me parece que es algo parecido a lo afirmado por Martin Wallraff $(2013,304)$ cuando dice que «la religiosità di Costantino non corrispondeva affatto a un'ortodossia di nessun tipo, certamente non a quella cristiana. L'intenzione dell'imperatore sarà stata quella di inserire il cristianesimo accanto alle altre religioni del suo impero in un nuovo tipo di religione imperiale». El propio Peter Brown (1972, 164) resumió, en otra ocasión, su juicio sobre el tema con estas escuetas palabras: "The change in the official religion of Rome took the form, not of a brutal rejection of the past, by an authoritarian régime, but a transformation in which

24 León Magno, In Nativitatem Domini, 7, 4; Id., Sermo de nat. Christi, I 7, 3, 4-5.

25 Gelasio, Epist. adversus Andromacum, 18.

26 Gelasio, Epist., 110, 1.

27 Gelasio, Epist., 100, 19. 
much of the Roman secular tradition was preserved $» .^{28}$ San Agustín afirmaba que "los bienes temporales y terrenales son competencia de los demonios y de las potestades de estas tinieblas ${ }^{29}{ }^{29}$ Es evidente que las divinidades politeístas y las potencias demoniacas, aunque expulsadas de sus lugares de culto tradicionales, continuaron viviendo en el imaginario popular y garantizando asistencia y éxito a quienes se dirigían a ellas con devoción. Si recordamos a Mauro Pesce cuando declara que las fronteras entre cristianos y judíos fueron establecidas en muchas ocasiones por teólogos y autoridades eclesiásticas o rabínicas (2011, 151), no estará de más compartir también el juicio de Rita Lizzi (2011, 472-473) de que «con Rufino (di Aquileia) nacque quel mito della fine improvvisa del paganesimo, intorno al quale tanta storiografia moderna e contemporanea ha tentato di ricostruire i particolari storici della inevitabile parabola dell'antica religione romana.$^{30}$ En la misma línea, N. McLynn en su conocida monografía sobre Ambrosio de Milán ha cuestionado la fuerza efectiva del cristianismo sobre el paganismo a finales del siglo IV, mucho menor de lo que los historiadores han acostumbrado a pensar sugestionados por la visión triunfalista que ofrecen la fuentes cristianas antiguas. Pero hay que plantearse también, añado yo, a qué tipo de paganismo nos estamos refiriendo cuando planteamos este tema, pues en un mismo ámbito geográfico como eran Hispania, Italia o la Galia convivían paganismos diferentes entre sí.

Nos encontramos ante un "territorio común" que von Harnack solo constató en el cristianismo hispano. Pienso que si Robert Markus hubiese fijado su atención en el análisis del cristianismo español que hace el historiador y teólogo alemán, hubiese experimentado la misma sorpresa y profundo desacuerdo que yo mismo sobre lo que denomina «mundanidad grosera». Es precisamente este "territorio común» lo que yo, siguiendo los pasos de Orosio he denominado «identidad romana» del cristianismo. $Y$, aunque no se sirve del término, a algo muy parecido alude Rita Lizzi Testa, de quien tomo textualmente esta cita:

Cuando la ruptura se hizo irreparable, y le vida cívica se plasmó en modos y ritmos cristianos, todo aquello que de las antiguas costumbres (istituti) paganas no había sido asimilado aún, confluyó en un espacio - destinado a variar con el paso de los siglos- que, en contraste con el elemento dominante cristiano, llegó a ser concebido como profano, e incluso laico pues se había perdido el recuerdo de la inseparable fusión de lo religioso y lo público donde había sido engendrado en origen (Lizzi Testa 2011, 190).

Pero no se trataba de algo nuevo en el siglo IV. Como ha escrito Julio Trebolle $(1993,587)$, «ya hacia el año 200 se había logrado una tal simbiosis entre cristianismo y paganismo que Tertuliano podía manifestar su temor a que el cristianismo se disolviera en una mezcla de platonismo, estoicismo y

28 Sobre el tema vide la recensión del mismo Brown 2011 al libro de Cameron 2011 y las diversas colaboraciones en Rita Lizzi Testa 2013 así como Acerbi 2017.

29 Agustín, Enarratio in Psalmum, XXXIV, 7.

30 Sobre el mismo argumento, Lizzi Testa 2014, con especial atención a la legislación contra los cultos paganos llegando a la conclusión de que, a pesar de los temores y amenazas contenidas en las leyes, "I'Impero rimase terra di contrasti religiosi, scenario di convivenze fra un cristianesimo trionfante e un tenace, seppur discreto, politeismo» (Lizzi Testa 2014, 138). aristotelismo, la koiné filosófica de la época». Para la misma época Robert Markus $(1990,27)$ interpretó con buen criterio lo que él denomina "exhibición retórica» de Tertuliano en su célebre exclamación Quid Athenae Hierosolymis? «no como la punta del iceberg de un sentimiento de hostilidad hacia la cultura profana, sino como la prueba consciente de la necesidad de reforzar en los cristianos el sentimiento de su propia identidad diferenciada en momentos de una rápida asimilación que parecía representar una amenaza para esta identidad».

La amenaza se consumó y ya antes de Constantino ser cristiano significaba ser leal al emperador o bien ser leal con la casa familiar, con la clase social a la que se pertenece o con el patrono del que se depende. Los procesos religiosos no pueden ser separados de las relaciones de poder, de la organización social y de los vínculos sociales o clientelares que dan coherencia al entramado social: el debate sobre la transmisión del poder bajo todas sus formas (riqueza, autoridad, etc.) entre las instituciones romanas y las instituciones eclesiásticas, entre los protagonistas profanos y los clérigos adquiere toda su trascendencia cuando estudiamos esta época que se suele denominar el final del mundo antiguo o, con más propiedad, antigüedad tardía. De la crisis del mundo antiguo surgió un mundo nuevo, el mundo de la catholica ecclesia y esta génesis no se llevó a cabo sin abandonos y recuperaciones, sin ambigüedades y contradicciones, sin magos, sacerdotes y santos. Me permito recoger este juicio de Cracco Ruggini (1998, 391-392):

In questo Occidente romano-barbarico e cristiano l'accento avrebbe continuato ancora a lungo a insistere sulla dimensione "universale» (politica oltre che religiosa) della Christianitas ereditata dalla Romanitas: fino a Carlomagno (primo realizzatore de un impero cristiano indipendente di quello di Bisanzio; fino a Ottone I, lui pure, come Carlo, incoronato imperatore dal papa di Roma nel 962 (il Sacro Romano Impero). Ma la cornice geografica di questa cristianità che si pretendeva "universale» s'era andata di fatto ristringendo sempre più, soprattutto a seguito dell'avanzare dell'Islam, lungo le coste mediterranee d'Africa e della contrapposizione ormai netta con Bisanzio. Finché la Christianitas non arrivò a coincidere con la Europa geografico-politica e a devenirne un concetto equipollente.

Concluyo al igual que comencé con una referencia a Orosio y a su romanismo cristiano. La identificación providencial Imperio-Cristianismo constituye el leitmotiv omnipresente de su concepción de la historia desde que, al inicio de su libro primero, identifica el reinado de Augusto con el nacimiento de Cristo. El libro VI es un completo desarrollo de toda una teología política del emperador Augusto donde, sirviéndome de las palabras de Eric Peterson $(1999,91)$, «este español provincial entrelazó Imperio y Cristianismo como tal vez nadie hizo, y los relacionó de una manera impresionante, vinculando Augusto a Cristo. Evidentemente con ello cristianiza a Augusto y romaniza a Cristo, que resulta ser un civis romanus». De hacer a Cristo un civis romanus a interpretar al obispo de Roma como el imperator de una Iglesia católica y romana, no hubo más que un paso. Me permito recordar que, cuando en 1305 los papas abandonaron Roma por Avignon, lo hicieron sobre el principio de que $u b i$ papa, ibi Roma, adaptando el lema acuñado por los juristas clásicos de que ubi Caesar, ibi Roma. Algunos siglos antes, 
la contemplación de algunos monumentos como el Coliseo, que aún seguían en pie, había inspirado al poeta anónimo citado en el siglo VII por Beda el Venerable estos bellos versos: Quamdiu stat Colisaeus / stat et Roma / Quando cadet Colisaeus / cadet Roma / Quando cadet Roma / cadet et mundus (Giardina y Vauchez 2000, 25). De algún modo, esto significaba evocar la creencia en la eternidad de Roma cantada por Virgilio (His... imperium sine fine dedi) de la que se sirvió el papa Gregorio VII para expresar el principio que garantizaba la identificación de la Iglesia con la respublica Romana: Quibus imperavit Augustus, imperat Cristus. Este principio permaneció tan vivo en las conciencias en el Occidente medieval que Dante al final del Purgatorio, -evocando, es cierto el cielo, no la tierra - no dudará en poner en boca de Beatriz: «E sarai meco sanza fine cive / di quella Roma onde Cristo è romano» (XXXII, 101-102). Esta idea alcanzó, a mi manera de ver, su mejor expresión en el arte altomedieval en este díptico de marfil del siglo $\mathrm{X}$, conocido como "Díptico de Rambona», en que Cristo crucificado se apoya en los lomos de la Loba capitolina.

FIGURA 1

Particulare del "Dittico di Rambona» (IX secolo) Dittico di Rambona, Siglo X. Biblioteca Apóstolica Romana

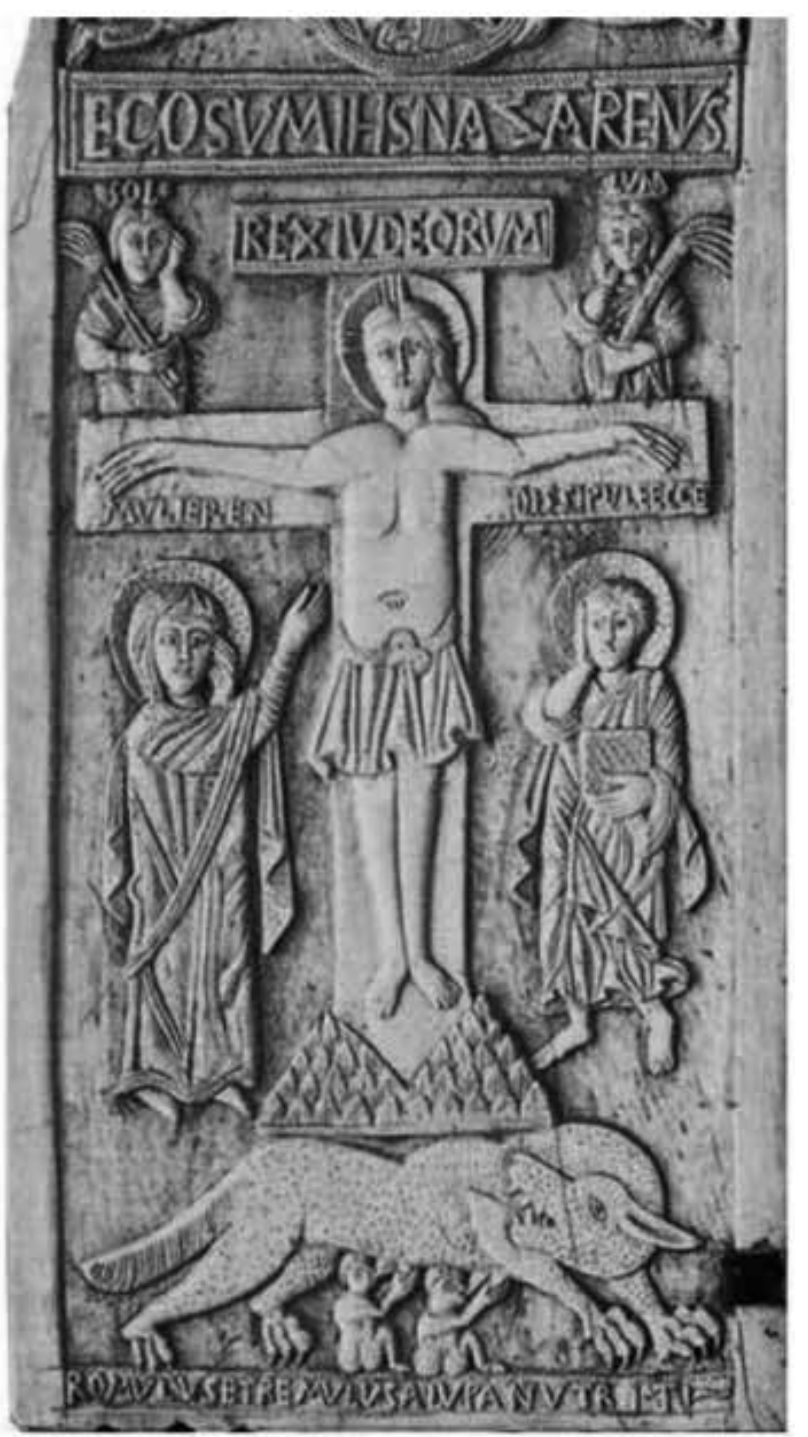

\section{BiBLIOGRAFÍA}

Acerbi, Silvia. 2017. «Pagani qui supersunt... (CTh 16, 10, 2): the End of Paganism and Apologetic Christian Triumphalism». En Dinamiche politico-ecclesiastiche nel Mediterraneo cristiano antico. Studi per Ramón Teja, ed. Silvia Acerbi y Giorgio Vespignani, 1-14. Roma: L'Erma di Bretschneider.

Andrés Pérez, Javier. 2014. La idea de la eternidad de Roma en la Antigüedad Tardía. Transformación urbana y percepción ideológica. Tesis doctoral. Universidad de Salamanca.

Blázquez, José María. 1996. «Características de la sociedad hispana del Bajo Imperio». En España romana, 365-393. Madrid: Cátedra.

Brown, Peter. 1972. Religion and Society in the Age of Saint Augustine. London: Faber and Faber.

Brown, Peter. 1974. Il mondo tardo antico. Da Marco Aurelio a Maometto. Torino: Einaudi

Brown, Peter. 2011. "Paganism: What We Owe the Christian». New York Review of Books LXVIII, 6: 68-72.

Cameron, Alan. 2011. The Last Pagans of Rome. Oxford - New York: Oxford University Press.

Canella, Tessa. 2017. Il peso della tolleranza. Cristianesimo antico e alterità. Brescia: Morcelliana.

Chastagnol, André y Noël Duval. 1972. "Les survivances du culte impérial dans l'Afrique du nord à l'epoque vandale». Bulletin de la Société nationale des Antiquaires de France: 194-198.

Clemente, Guido. 1994. «Cristianesimo e classi dirigenti prima e dopo Costantino». En La parte migliore del genere humano. Aristocrazie, potere e ideologia nell'Occidente tardoantico, ed. Sergio Roda, 5978. Torino: Scriptorium.

Cracco Ruggini, Lellia. 1998. «L'ecumenismo politico nel IV secolo d. C., in Oriente e in Occidente». En L'ecumenismo politico nella coscienza dell'Occidente. Alle radici della casa comune europea, II, 383-395. Roma: L'Erma di Bretschnaider.

De Clercq, Victor. 1954. Ossius of Cordoba. A Contribution to the History of the Constantine Period. Washington D.C.: Catholic University of America.

Duchesne, Louis. 1887. "Le concile d'Elvire et les flamines chrétiens». En Melanges Rénier. Bibliothéque de l'Ecole des Hautes Études, 159-174. París: Vieweg.

Fernández Ubiña, José. 1993. «Le concile d'Élvire et l'esprit du paganisme». Dialogues d'Histoire ancienne 19 (1): 309-318.

Fernández Ubiña, José y María del Mar Marcos, eds. 2007. Libertad e intolerancia religiosa en el Imperio romano. Madrid: Universidad Complutense.

Fontaine, Jacques. 1981. «Panorama espiritual del Occidente peninsular en los siglos IV y V: por una nueva problemática del priscilianismo». En Actas de la Primera Reunión Gallega de Estudios Clásicos, 185-209. Santiago de Compostela: Universidad de Santiago de Compostela.

Giardina, Andrea y André Vauchez. 2000. II mito di Roma. Da Carlo Magno a Mussolini. Roma: Laterza.

Harnack, Adolf von. 1986. Missione e propagazione del cristianesimo nei primi tre secoli. Cosenza: Lionello Giordano Ed.

Inglebert, Hervé. 1996. Les Romains Chrétiens face à I'histoire de Rome. Histoire, Christianisme et Romanités en Occidente dans l'Antiquité tardive (III-V siècles). Paris: Institut d'Études Augustiniennes.

Lizzi Testa, Rita. 2009a. «Dal conflitto al dialogo: nuove prospettive sulle relazioni tra pagani e cristiani in Occidente alla fine del IV secolo». En Trent'anni di studi sulla tarda Antichità, ed. Ugo Criscuolo y Lucio De Giovanni, 167-190. Napoli: D’Auria.

Lizzi Testa, Rita. 2009b. «La conversione dei cives, la evangelizzazione dei rustici: alcuni esempli fra IV e V secolo». En Città e campagna nei secoli altomedievale (Settimane di studio della Fondazione Centro italiano di studi sull'alto Medioevo, 56), 115-150. Spoleto: Sede della Fondazione.

Lizzi Testa, Rita. 2011. "Legislazione imperiale e reazione pagana: i limiti del conflitto». En Pagans and Christians in the Roman Empire: The Breaking of a Dialogue (IV-VI Century A. D.), ed. Peter Brown y Rita Lizzi Testa, 467-492. Wien - Berlin: Lit Verlag. 
Lizzi Testa, Rita, ed. 2013. The Strange Death of Pagan Rome. Reflections on a Historiographical Controversy. Turnhout: Brepols.

Lizzi Testa, Rita. 2014. "Il terrore delle leggi in difesa dell'insatiabilis honor della Chiesa: la retorica della rappresentazione cristiana dello Impero». En Política, religión y legislación en el Imperio Romano, ed. María Victoria Escribano y Rita Lizzi Testa, 117-138. Bari: Edipuglia.

Marcos, María del Mar. 2008. "La Iglesia y el fin de la Hispania romana». En Entre fenicios y visigodos. La historia antigua de la Península Ibérica, dir. Jaime Alvar, 615-633. Madrid: La Esfera de los Libros.

Marcos, María del Mar. 2013. "The Debate on Religious Coercion in Ancient Christianity». Chaos et Kosmos 14. http://www.chaosekosmos.it/pdf/2013_15.pdf

Markus, Robert. 1990. The End of Ancient Christianity. Cambridge: Cambridge University Press.

Pesce, Mauro. 2011. Da Gesù al cristianesimo. Brescia: Morcelliana.

Peterson, Erik. 1999. El monoteísmo como problema político. Madrid: Trotta

Rahner, Hugo. 1990. Miti greci nell'interpretazione cristiana. Bologna: Edizioni Dehoniane.

Rouselle, Aline. 1997. "Suggestions pour l'étude du paganisme de 191 à 325». Pallas, revue d'études antiques: 11-19.

Sachot, Maurice. 1998. L'invention du christianisme. Paris: Odile Jacob.

Sotomayor, Manuel. 1982. «Penetración de la Iglesia en los medios Rurales de la España tardorromana y visigoda». En Cristianizzazione ed organizzazione ecclesiastica delle campagne nell'Alto Medioevo: espansione e resistenze (Settimane di studio della Fondazione Centro italiano di studi sull'alto Medioevo, 28), 639-683. Spoleto: Sede della Fondazione.
Stark, Rodney. 2009. La expansión del cristianismo. Un estudio sociológico. Madrid: Trotta.

Stroumsa, Guy Gedalyah. 1994. «Early Christianity as Radical Religion: Context and Implications». Israel Oriental Studies 14: 173-193.

Stroumsa, Guy Gedalyah. 2017. Religions d'Abraham. Histoires croisées. Genève: Labor et Fides.

Teja, Ramón. 2000. «Una mirada a los estudios sobre el cristianismo antiguo en España». En El cristianismo. Aspectos históricos de su origen y difusión en Hispania. Actas del Symposium de VitoriaGazteiz, ed. Juan Santos y Ramón Teja, 29-36. Vitoria: Universidad del País Vasco.

Teja, Ramón. 2015. «¿Romanos o cristianos? La apropiación de la identidad romana por el cristianismo». En Fronteiras e identidades no Império Romano. Aspectos sociopolíticos e religiosos, Gilvan Ventura da Silva y Érica Cristhyane Morais da Silva, 93-118. Vitoria: GM Editora.

Trebolle, Julio. 1993. La biblia judía y la biblia cristiana. Introducción a la historia de la Biblia. Madrid: Trotta.

Wallraff, Martin. 2013. "Santa Sofia-Sofia dell'imperatore. Note su Costantino e la sua nuova capitale sul Bosforo». En Polidoro. Studi offerti ad Antonio Carile I, ed. Giorgio Vespignani, 291-304. Spoleto: Fondazione Centro Italiano di Studi Sull'alto Medioevo.

Zocca, Elena. 2015. «Percezioni della crisi e scansioni del tempo fra mondo classico e cristianesimo». Studi e Materiali di Storia delle Religioni 81 (1): 210-237.

Zweig, Stefan. 2001. Castellio contra Calvino. Conciencia contra violencia. Barcelona: El Acantilado. 
